This work is on a Creative Commons Attribution 4.0 International (CC BY 4.0) International license, https://creativecommons.org/licenses/by/4.0/. Access to this work was provided by the University of Maryland, Baltimore County (UMBC) ScholarWorks@UMBC digital repository on the Maryland Shared Open Access (MD-SOAR) platform.

Please provide feedback

Please support the ScholarWorks@UMBC repository by emailing scholarworks-group@umbc.edu and telling us

what having access to this work means to you and why it's important to you. Thank you. 


\title{
Engineering Yarrowia lipolytica as a Chassis for De Novo Synthesis of Five Aromatic-Derived Natural Products and Chemicals
}

\author{
Yang Gu, Jingbo Ma, Yonglian Zhu, Xinyu Ding, and Peng Xu* \\ Cite This: https://dx.doi.org/10.1021/acssynbio.0c00185 \\ Read Online
}

ABSTRACT: Yarrowia lipolytica is a novel microbial chassis to upgrade renewable low-cost carbon feedstocks to high-value commodity chemicals and natural products. In this work, we systematically characterized and removed the rate-limiting steps of the shikimate pathway and achieved de novo synthesis of five aromatic chemicals in Y. lipolytica. We determined that eliminating amino acids formation and engineering feedback-insensitive DAHP synthases are critical steps to mitigate precursor competition and relieve the feedback regulation of the shikimate pathway. Further overexpression of heterologous phosphoketolase and deletion of pyruvate kinase provided a sustained metabolic driving force that channels E4P (erythrose 4-phosphate) and PEP (phosphoenolpyruvate) precursors through the shikimate pathway. Precursor competing pathways and byproduct formation pathways were also blocked by inactivating chromosomal genes. To demonstrate the utility of our engineered

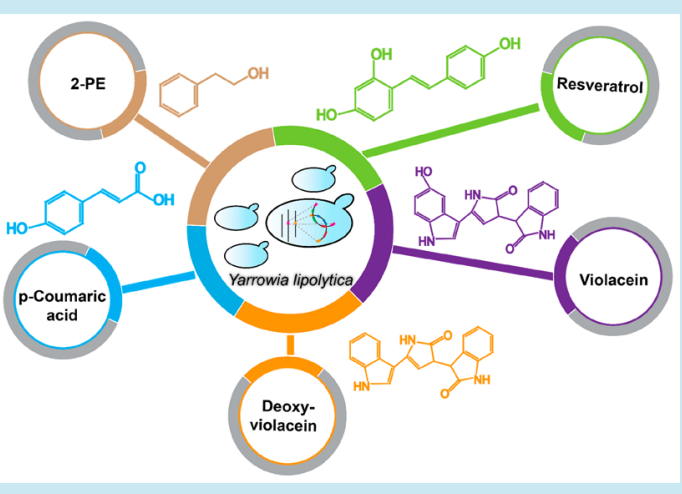
chassis strain, three natural products, 2-phenylethanol (2-PE), p-coumaric acid, and violacein, which were derived from phenylalanine, tyrosine, and tryptophan, respectively, were chosen to test the chassis performance. We obtained $2426.22 \pm 48.33 \mathrm{mg} / \mathrm{L}$ of 2 -PE, $593.53 \pm 28.75 \mathrm{mg} / \mathrm{L}$ of $p$-coumaric acid, $12.67 \pm 2.23 \mathrm{mg} / \mathrm{L}$ of resveratrol, $366.30 \pm 28.99 \mathrm{mg} / \mathrm{L}$ of violacein, and $55.12 \pm 2.81 \mathrm{mg} / \mathrm{L}$ of deoxyviolacein from glucose in a shake flask. The $2-\mathrm{PE}$ production represents a 286 -fold increase over the initial strain $(8.48 \pm 0.50 \mathrm{mg} / \mathrm{L})$. Specifically, we obtained the highest 2 -PE, violacein, and deoxyviolacein titer ever reported from the de novo shikimate pathway in yeast. These results set up a new stage of engineering Y. lipolytica as a sustainable biorefinery chassis strain for de novo synthesis of aromatic compounds with economic values.

KEYWORDS: shikimate pathway, microbial chassis, de novo synthesis, aromatic metabolism, feedback regulation, metabolic engineering

$\mathrm{Y}$ arrowia lipolytica, as a "generally regarded as safe" (GRAS) yeast, ${ }^{1}$ has been extensively engineered for the production of oleochemicals, fuels, and commodity chemicals. $^{2-5}$ The abundant acetyl-CoA and malonyl-CoA precursors in $Y$. lipolytica have been harnessed for synthesizing plant secondary metabolites in recent years, including flavonoids, ${ }^{6-9}$ polyketides, ${ }^{10,11}$ polyunsaturated fatty acids, $^{12,13}$ and isoprenoids. ${ }^{14-17}$ A large collection of customized genetic toolkits, including Golden-gate cloning, $^{18-20}$ genome integration, ${ }^{6,21,22}$ CRISPR-Cas9/Cpf1 genome editing, ${ }^{23-25}$ transposons, ${ }^{26}$ auxotrophic markers, ${ }^{27}$ and promoter libraries ${ }^{28-30}$ have accelerated our ability to perform targeted genetic manipulations. Different from Saccharomyces cerevisiae, Y. lipolytica lacks Crabtree effects generating no overflowed metabolism toward ethanol under high glucose conditions, ${ }^{31}$ which might be more suitable for high gravity fermentation and process control. Y. lipolytica is reported to valorize a broad range of cheap and renewable feedstocks, ${ }^{32,33}$ including sugars, volatile fatty acids, alkanes, and municipal organic wastes. This substrate flexibility provides us an environmentally friendly approach to upgrade low-value carbons to high value chemicals with reduced carbon footprint and improved process economics.
Aromatic compounds have wide applications ranging from health care to the food industry, nutraceutical supplements, and pharmaceutical intermediates, which collectively represent a multibillion-dollar global market. ${ }^{34-37}$ Although metabolically engineered Escherichia coli has achieved gram-per-liter levels of aromatic compounds, primarily phenylpropanoids, ${ }^{38,39}$ yeast proves to be a more attractive host, due to its GRAS status, robust cell growth, tolerance of harsh conditions (such as low $\mathrm{pH}$ and high osmolarity), and the spatially organized subcellular compartment for regio- or stereoactivity of cytochrome P450 enzymes. ${ }^{7,34,37,40} \mathrm{Up}$ to date, various metabolic engineering strategies have been implemented in E. coli and S. cerevisiae to improve aromatics production, including expression of the feedback-insensitive DAHP synthases ${ }^{41}$ and chorismite synthase, enhancing the

Received: April 3, 2020

Published: July 10, 2020 


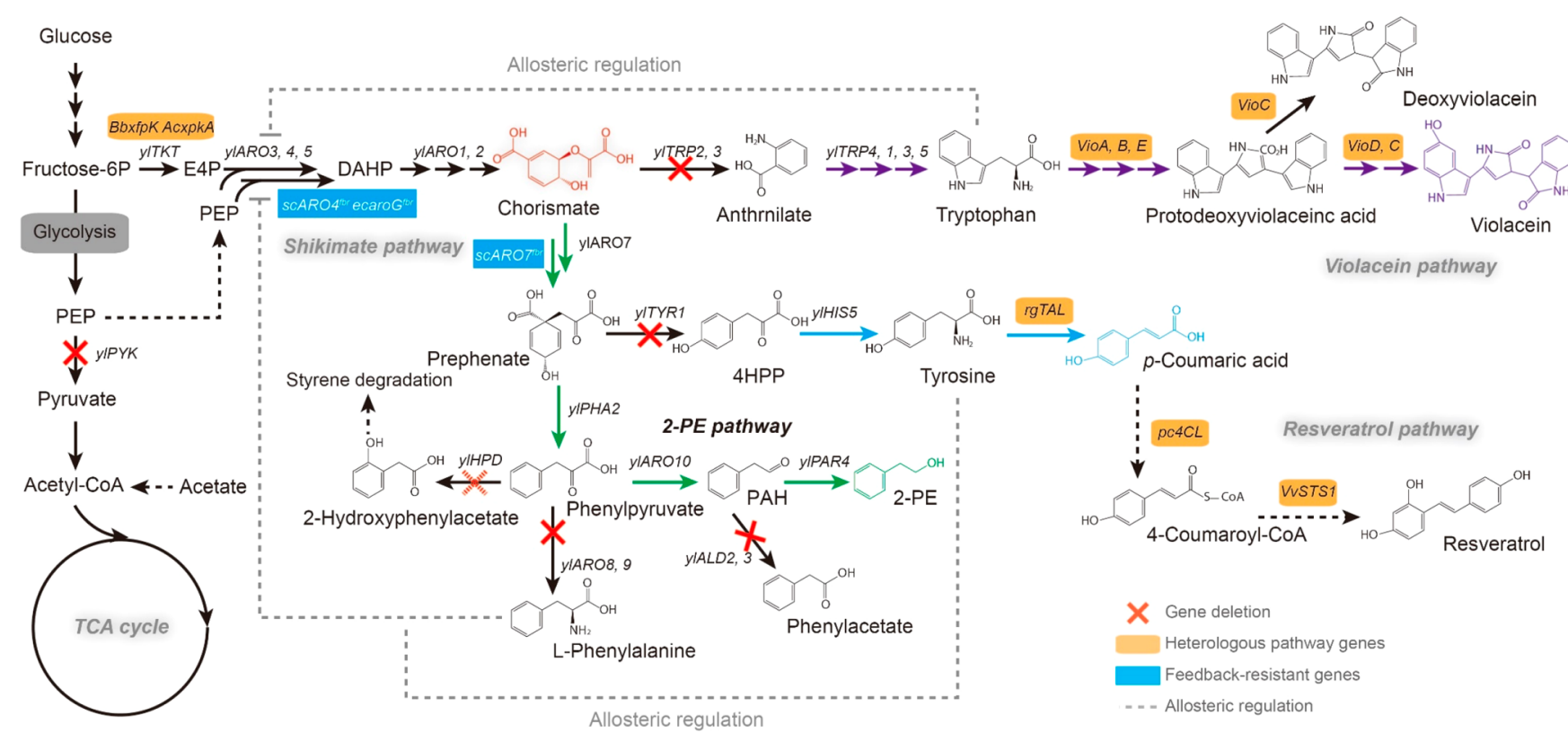

Figure 1. De novo biosynthetic routes for 2-PE, p-coumaric acid, resveratrol, and violacein production through the shikimate pathway in $Y$. lipolytica. PEP, phosphoenolpyruvate; E4P, erythrose-4P; DAHP, 3-deoxy-arabino-heptulonate-7-phosphate; 4HPP, 4-hydroxyphenylpyruvate; PAH, phenylacetaldehyde; 2-PE, 2-phenylethanol; ylTKT, transketolase; ylPYK, pyruvate kinase; ylARO3, 3-deoxy-7-phosphoheptulonate synthase; ylARO4, 3-deoxy-7-phosphoheptulonate synthase; ylARO5, 3-deoxy-7-phosphoheptulonate synthase; ylARO1, pentafunctional AROM polypeptide; ylARO2, chorismate synthase; ylARO7, chorismate mutase; ylTRP2, anthranilate synthase; ylTRP3, anthranilate synthase; ylTRP4, anthranilate phosphoribosyltransferase; ylTRP1, phosphoribosylanthranilate isomerase; ylTRP5, tryptophan synthase; ylTYP1, prephenate dehydrogenase; ylARO8, aromatic amino acid aminotransferase; ylARO9, aromatic amino acid aminotransferase; ylPHA2, prephenate dehydratase; ylARO10, phenylpyruvate decarboxylase; ylPAR4, phenylacetaldehyde reductases; ylHPD, 4-hydroxyphenylpyruvate dioxygenase; ylALD2, aldehyde dehydrogenase; ylALD3, aldehyde dehydrogenase; scARO $7^{\mathrm{fbr}}$, the feedback-resistant chorismate mutase from S. cerevisiae; BbxfpK, phosphoketolase from Bifidobacterium breve; AcxpkA, phosphoketolase from Acidobacterium capsulatum; ecaroG ${ }^{\mathrm{fbr}}$, the feedback-resistant 3-deoxy7-phosphoheptulonate synthase from E. coli; scARO4 ${ }^{\text {fbr }}$, the feedback-resistant 3-deoxy-7-phosphoheptulonate synthase from S. cerevisiae; rgTAL, tyrosineammonia-lyase from Rhodotorula toruloides; pc4CL, 4-coumarate-CoA ligase from Petroselinum crispum; VvSTS1, resveratrol synthase from Vitis vinifera; VioA, tryptophan oxidase; VioB/VioE, protodeoxyviolaceinate synthase; VioD, protodeoxyviolaceinate monooxygenase; VioC, violacein synthase. All violacein pathway genes were amplified from the genomic DNA of Chromobacterium violaceum. Right corner shows the chromosomal integration of the chosen pathways.
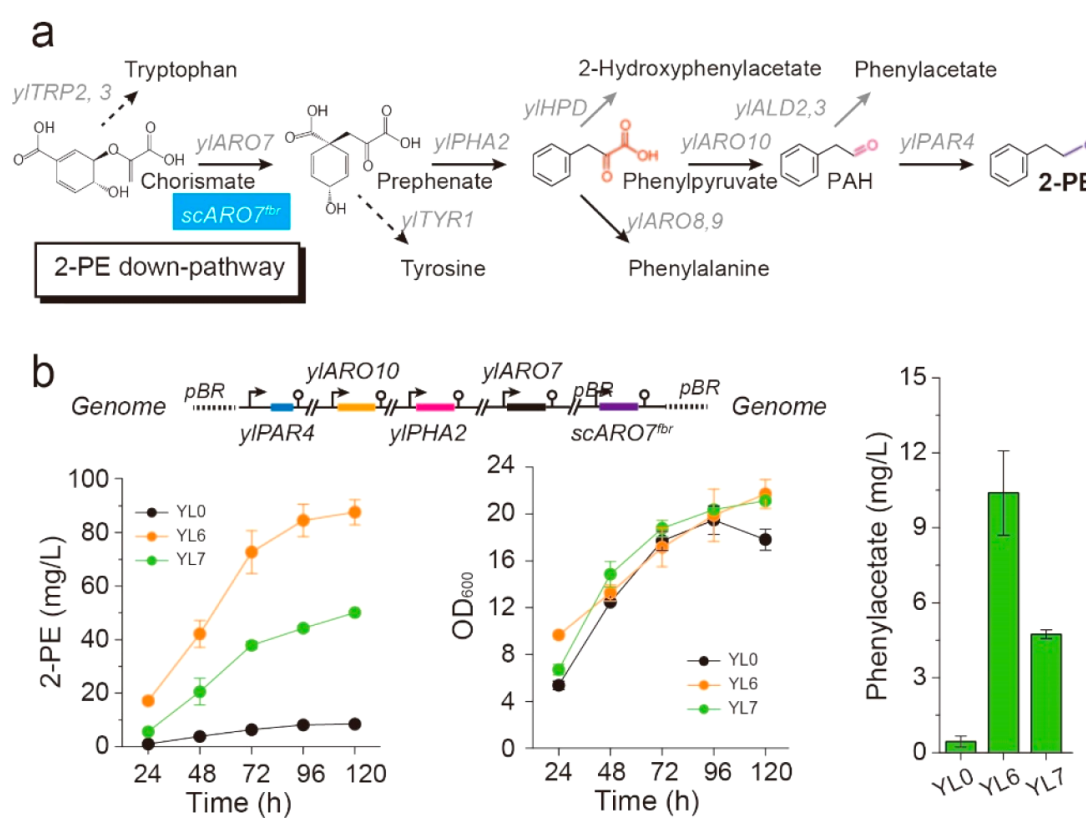

Figure 2. Validating and relieving bottlenecks in the Ehrlich pathway for 2-PE synthesis. (a) Enzyme cascade reactions of 2-PE production from chorismate. (b) Time profiles of 2-PE titer, cell growth, and phenylacetate titer of strains carrying the 2-PE pathway. All experiments were performed in triplicate and error bars represent standard deviations (SD). 


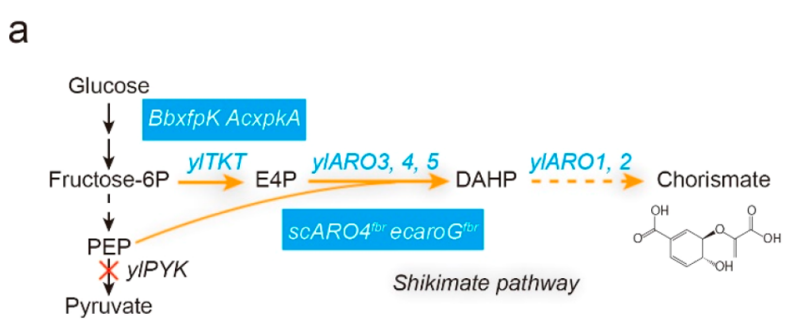

C

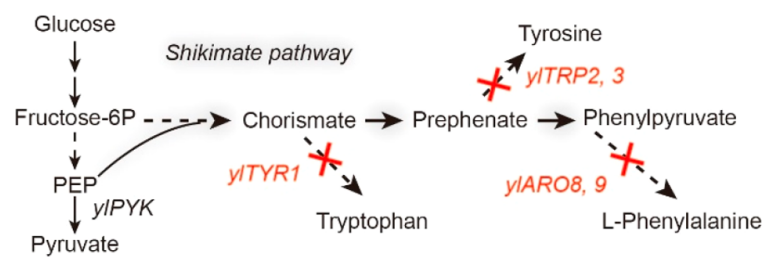

e

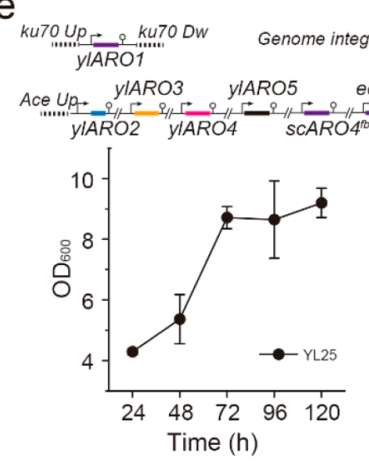

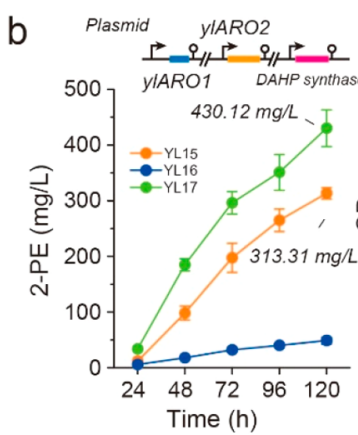
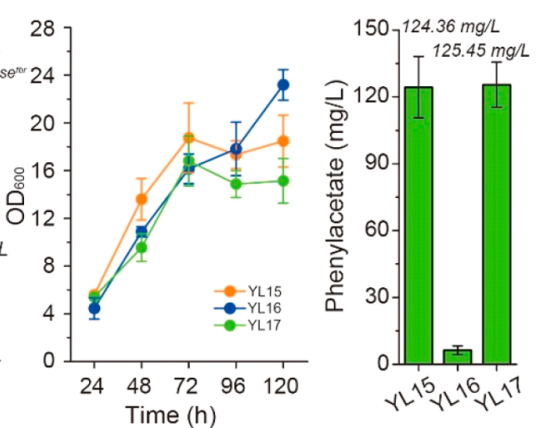

d
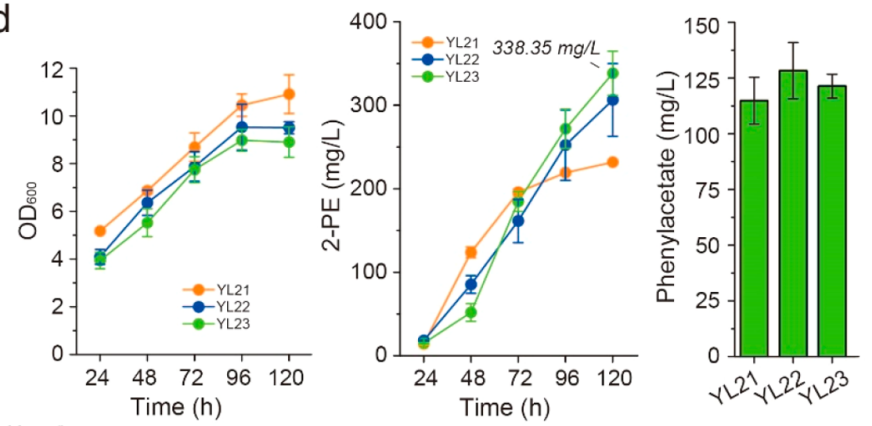

Figure 3. Relieving bottlenecks in shikimate pathway. (a) The shikimate pathway of Y. lipolytica. (b) Phenylacetate, 2-PE, and cell growth profile of strains coexpressing ylARO1, ylARO2, and the feedback-resistant DAHP synthases encoding genes. (c) Deletion of amino acids, including phenylalanine, tryptophan, and tyrosine in Y. lipolytica. (d) Phenylacetate, 2-PE, and cell growth profile of mutant strains deficient in phenylalanine, tryptophan, and tyrosine formation. (e) Phenylacetate, 2-PE, and cell growth profile of mutant strains (deficient in phenylalanine, tryptophan, and tyrosine formation) expressing the shikimate pathway. All experiments were performed in triplicate, and error bars represent standard deviations $(\mathrm{SD})$.

shikimate pathway ${ }^{42}$ and modular microbial coculture. ${ }^{43-45} \mathrm{~A}$ number of studies have been focused on optimizing the endogenous Ehrlich pathway to produce 2-phenylethanol up to 3-6 g/L; ${ }^{46-48}$ however, the expensive precursor L-phenylalanine was fed into the biphasic bioreactors, ${ }^{49,50}$ restricting its economic potential for large-scale production. The highest titer of 2-phenylethanol production from the de novo shikimate pathway was reported recently as $1.58 \mathrm{~g} / \mathrm{L}(13 \mathrm{mM})$ from S. cerevisiae. ${ }^{41}$ There is a pressing need to explore the metabolic potential of alternative yeast for aromatics production.

In this work, we attempted to engineer the nonconventional oleaginous yeast (Y. lipolytica) as a competitive platform host to produce aromatic derivatives (Figure 1). With 2-phenylethanol (2-PE) as the testbed molecule, we systematically characterized and removed the bottlenecks of the endogenous shikimate pathway, resulting in the production of $2426.22 \pm$ $48.33 \mathrm{mg} / \mathrm{L}(19.85 \pm 0.40 \mathrm{mM})$ of 2 -PE from glucose, the highest titer ever reported from the de novo shikimate pathway. Using this yeast as chassis, we further redirected the shikimate flux toward other aromatics and achieved high titers of $p$ coumaric acid $(593.53 \pm 28.75 \mathrm{mg} / \mathrm{L})$, violacein $(366.30 \pm$ $28.99 \mathrm{mg} / \mathrm{L}$, highest titer reported in yeast), and deoxy- violacein $(55.12 \pm 2.81 \mathrm{mg} / \mathrm{L}$, highest titer reported in yeast $)$ in shaking flasks, indicating the superior metabolic potential of $Y$. lipolytica as an aromatics-producing host. This report highlights the prominent metabolic characteristics of Y. lipolytica as a chassis for production of various aromatics and natural products with economic values.

\section{RESULTS AND DISCUSSIONS}

De Novo Synthesis of 2-PE from Shikimate Pathway. In this work, the $Y$. lipolytica endogenous metabolite 2phenylethnol (2-PE, an aromatic alcohol that is widely used as flavor and fragrance agent) was chosen as a target molecule to determine the bottlenecks of the shikimate pathway. 2-PE synthesis is a metabolic branch derived from shikimate pathway, in which 2-PE is synthesized through four enzymedependent cascade reactions starting from chorismate (Figure 2a). To identify the potential limiting-steps in 2-PE synthesis, we first systematically overexpressed all genes that are involved in 2-PE synthesis under the control of strong constitutive pTEF-intron promoter, $^{30}$ including genes ylPAR4 (YALIOD07062g, encoding phenylacetaldehyde reductase), ylARO10 (YALIOD06930g, encoding phenylpyruvate decar- 
boxylase), ylPHA2 (YALIOB17336g, encoding prephenate dehydratase), and ylARO7 (YALIOE17479g, encoding chorismate mutase). Besides gene ylARO10, individual overexpression of genes $y l P A R 4, y l P H A 2$, and $y l A R O 7$ did not result in a significant increase in 2-PE titer (Supplementary Figure S2); however, combining all four genes (strain YL5) led the strain to produce $55.53 \pm 0.85 \mathrm{mg} / \mathrm{L}$ of 2 -PE from glucose (Supplementary Figure S2), a 6.55-fold increase in comparison with the control strain (without any gene overexpression, 8.48 $\pm 0.50 \mathrm{mg} / \mathrm{L}$ ), indicating that the four enzymes in the Ehrlich pathway are essential to channel the carbon flux toward 2-PE synthesis. In addition, chorismate mutase (ARO7) is known to be strictly feedback inhibited by aromatic acids. ${ }^{42}$ To resolve this issue, introduction of a feedback-resistant chorismate mutase ScARO7 ${ }^{\mathrm{G} 141 \mathrm{~S}}$ originating from Saccharomyces cerevisiae further improved 2-PE production up to $87.63 \pm 4.67 \mathrm{mg} / \mathrm{L}$ (strain YL6, Figure 2b), which was consistent with the previous report. ${ }^{51}$ We have configured the Ehrlich pathway to achieve de novo 2-PE synthesis from glucose with enhanced titer.

We subsequently optimized the shikimate pathway to unlock the potential of $Y$. lipolytica for production of aromatic compounds. The entire Ehrlich pathway for 2-PE synthesis contains multiple genes with total size more than $16000 \mathrm{bp} .^{52}$ To simplify the genetic manipulations, we integrated the 2-PE pathway at the genomic YALIOE30965g loci (encoding acetylCoA hydrolase) with the integration plasmid pURLA-ylPAR4$y l A R O 10-y l A R O 7-y l P H A 2-s c A R O 7^{G 141 S}$. The resultant strain YL7 produced $50.13 \pm 0.62 \mathrm{mg} / \mathrm{L}$ of $2-\mathrm{PE}$ from glucose (Figure 2b). In Y. lipolytica, shikimate pathway is consisted of seven enzymatic steps, which starts from precursors erythrose4-phosphate (E4P) and phosphoenolpyruvate (PEP) and ends up with chorismate (Figure 1). By overexpressing genes ylARO1 (YALIOF12639g, encoding pentafunctional aromatic protein), ylARO2 (YALIOD17930g, encoding bifunctional chorismate synthase), ylARO3 (YALIOB20020g, encoding DAHP synthase), ylARO4 (YALIOB22440g, encoding DAHP synthase), and ylARO5 (YALIOC06952g, encoding DAHP synthase) in strain YL7, we generated strains YL8, YL9, YL10, YL11, and YL12 that were able to produce 2-PE with titers at $62.53 \pm 1.28,52.80 \pm 2.18,59.49 \pm 1.70,54.71 \pm 0.87$, and $57.16 \pm 2.64 \mathrm{mg} / \mathrm{L}$ (Supplementary Figure S3), respectively. Strains YL8, YL10, and YL12 showed slight increase of 2-PE titer compared with strain YL7. However, by simultaneous overexpression of genes $y l A R O 1$ and $y l A R O 2,2-\mathrm{PE}$ production was increased to $84.64 \pm 4.42 \mathrm{mg} / \mathrm{L}$ (strain YL13, Supplementary Figure S3). Further overexpression of $y l A R O 3, y l A R O 4$, and $y l A R O 5$ did not have a significant effect on 2-PE titer (strain YL14, $78.28 \mathrm{mg} / \mathrm{L}$, Supplementary Figure S3), which is possibly due to the allosteric regulation of DAHP synthase by aromatic amino acids, a common phenomenon in S. cerevisiae. ${ }^{34,42}$

Relieving Metabolic Bottlenecks in the Shikimate Pathway. Heterologous DAHP synthases scARO ${ }^{\mathrm{K} 229 \mathrm{~L}}$ (originating from S. cerevisiae), AroG ${ }^{\mathrm{L} 175 \mathrm{D}}$, and $\operatorname{AroG}^{\mathrm{S} 180 \mathrm{~F}}$ (originating from E. coli) previously have been shown to be feedback-resistant of aromatic amino acids regulation. ${ }^{42} \mathrm{We}$ next introduced three variants of the feedback-resistant DAHP synthases into the 2-PE chassis strain, and generated strains YL15, YL16, and YL17. Shake flask cultivation of strains YL15, YL16, and YL17 led to the production of $313.13 \pm 10.16$, $48.70 \pm 5.92$, and $430.11 \pm 33.05 \mathrm{mg} / \mathrm{L}$ of $2-\mathrm{PE}$ (Figure $3 \mathrm{a}, \mathrm{b}$ ), respectively. This result clearly demonstrates that over- expression of $\mathrm{scARO}^{\mathrm{K} 229 \mathrm{~L}}$ and $\mathrm{AroG}^{\mathrm{S} 180 \mathrm{~F}}$ are effective to remove the shikimate pathway bottleneck in $Y$. lipolytica. Likewise, the results indicated the importance of relieving allosteric regulation of DAHP synthase to increase carbon flux toward shikimate pathway.

On the other hand, we sought to eliminate the synthesis of aromatic amino acids byproducts, including phenylalanine, tryptophan, and tyrosine. For this purpose, five genes (Figure 3c) were chosen as knockout targets, including $y l T Y R 1$ (YALIOF17644g, encoding prephenate dehydrogenase), ylTRP2 (YALIOD11110g, encoding anthranilate synthase), ylTRP3 (YALIOE14751g, encoding anthranilate synthase), ylARO8 (YALIOE20977g, encoding aromatic amino acid aminotransferase), and ylARO9 (YALIOC05258g, encoding aromatic amino acid aminotransferase). By sequentially deleting $y l T Y R 1, y l T R P 2, y l T R P 3, y l A R O 8$, and $y l A R O 9$ in strain polfk (which is Ku70-deficient), we got strains YL18 (auxotroph of tryptophan), YL19 (auxotroph of tryptophan and tyrosine), and YL20 (auxotroph of tryptophan, tyrosine and phenylalanine). Then the de novo 2-PE pathway (ylPAR4ylARO10-ylARO7-ylPHA2-scARO $7^{G 141 S}$ ) was introduced into these auxotrophic strains (YL18, 19, and 20), leading to strains YL21, YL22, and YL23. In comparison to the parental strain YL6 (87.63 $\pm 4.67 \mathrm{mg} / \mathrm{L}$ of 2-PE titer), strains YL21, YL22, and YL23 led to 2-PE production (Figure $3 \mathrm{~d}$ ) increased by 2.65-fold (231.84 $\pm 1.46 \mathrm{mg} / \mathrm{L}), 3.49$-fold $(306.30 \pm 43.57$ $\mathrm{mg} / \mathrm{L})$, and 3.86 -fold $(338.35 \pm 26.41 \mathrm{mg} / \mathrm{L})$, respectively, despite that negative effect was observed in the cell growth. This result suggests that blocking of aromatic amino acids formation may further relieve allosteric regulation of DAHP synthase by L-Phe, L-Tyr, and L-Trp, and simultaneously mitigate precursor competition.

Taken together, we have proved that introduction of feedback-resistant heterologous DAHP synthases and blocking aromatic amino acids formation are both effective to debottlenecking the shikimate pathway in Y. lipolytica. We next combined these two strategies to boost the 2-PE yield. Genes encoding $y l A R O 1$ and $y l A R O 2-y l A R O 3-y l A R O 4-$ $y$ lARO5-scARO4 ${ }^{\mathrm{K} 229 \mathrm{~L}}$-aroG ${ }^{\mathrm{S} 180 \mathrm{~F}}$ were sequentially integrated at genome loci of $k u 70$ and YALIOE30965g, to generate the chassis strain YL24. By expression of the 2-PE pathway (ylPAR4-ylARO10-ylARO7-ylPHA2-scARO7 ${ }^{\text {G141S }}$ ) in strain YL24, the engineered strain produced $508.58 \pm 26.52 \mathrm{mg} / \mathrm{L}$ of 2-PE (strain YL25, Figure 3e), which was 1.18-fold, 1.50fold, and 59.97-fold increase over the YL17, YL23, and the starting strain YL0, respectively.

On the other hand, the operation of shikimate pathway is driven by the upstream precursors erythrose-4-phosphate (E4P, that is derived from pentose phosphate pathway) and phosphoenolpyruvate (PEP, that is derived from glycolysis). To further unlock the shikimate pathway, we next turned to rewire the carbon flows in the central carbon metabolism to optimize the supply of both E4P and PEP.

Removing Pentose Phosphate Pathway Bottleneck to Boost Precursor E4P. Metabolic flux analysis indicates that the available carbon flux toward E4P is as least 1 order of magnitude lower than the flux to PEP in yeast, ${ }^{34}$ which suggested the availability of E4P is the key step to maximizing flux to shikimate pathway. Overexpression of gene $y l T K T$ (YALIOE06479g, encoding transketolase) improved 2-PE titer to $598.36 \pm 0.46 \mathrm{mg} / \mathrm{L}$ (strain YL26, Supplementary Figure S4), a 1.18-fold increase over the strain YL25. This result indicates that the supply of E4P indeed was a bottleneck. 

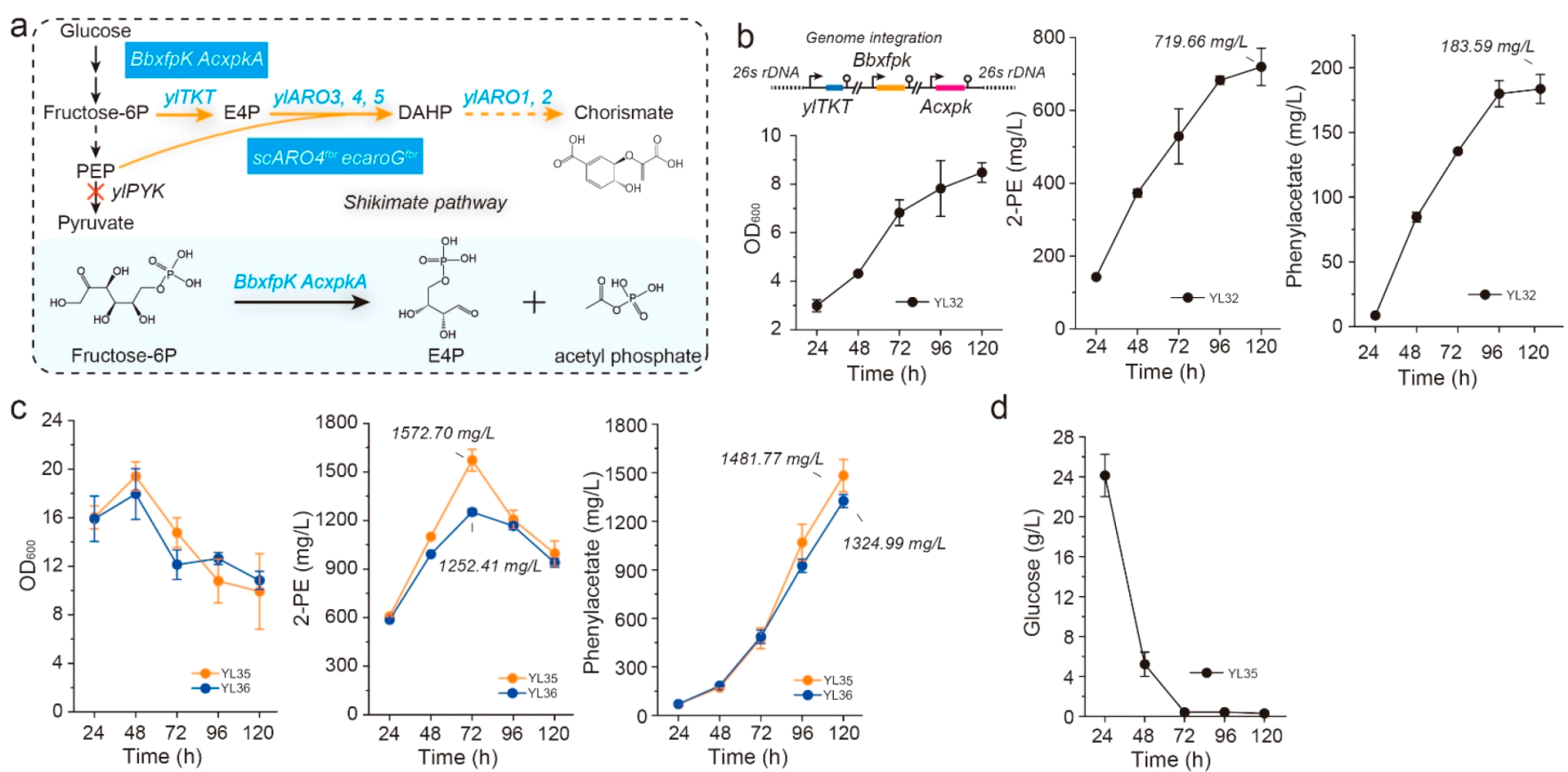

d
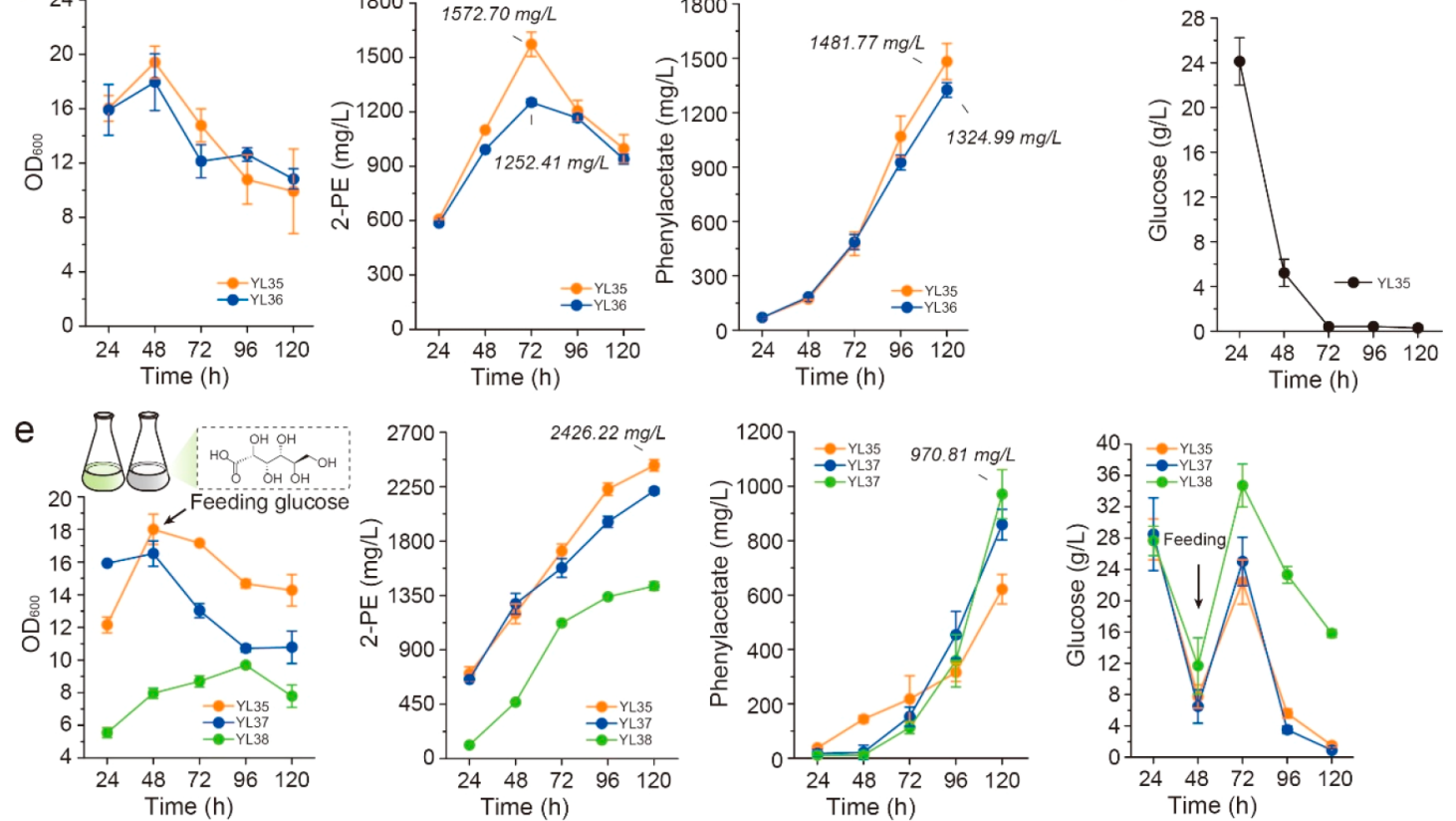

Figure 4. Rewiring carbon distribution toward precursors E4P and PEP. (a) Phosphoketolases provide precursor E4P to drive shikimate pathway. (b) Time profiles of 2-PE, cell growth, and phenylacetate of strains with chromosomal integration of transketolase ylTKT, phosphoketolases BbxfpK, and AcxpkA at genomic 26s rDNA sites. (c) Time profile of 2-PE, cell growth, and phenylacetate of strains with pyruvate kinase ylPYK deletion in YPD medium. (d) Time profiles of glucose consumption of strain YL35. (e) Improving 2-PE titer by feeding glucose and minimizing byproduct phenylacetate by deleting aldehyde dehydrogenase. All experiments were performed in triplicate, and error bars represent standard deviations (SD).

In the pentose phosphate pathway, phosphoketolase splits fructose-6-phosphate into E4P and acetyl-phosphate (Figure 4 a). ${ }^{34,53-55}$ In a recent study, overexpression of heterologous phosphoketolase BbxfpK from Bifidobacterium breve led to a 5.4-fold increase of intracellular E4P concentration in S. cerevisiae. ${ }^{53}$ We therefore introduced the codon-optimized phosphoketolase BbxfpK and AcxpkA (originating from Acidobacterium capsulatum) into our yeast chassis to generate strains YL27 and YL28, respectively. However, we observed declined 2-PE production (Supplementary Figure S4) in both strains YL27 (191.72 $\pm 7.97 \mathrm{mg} / \mathrm{L}$ of 2PE) and YL28 (146.76 $\pm 9.64 \mathrm{mg} / \mathrm{L}$ of $2 \mathrm{PE}$ ). As plasmids' genetic instability (i.e., unequal distribution/propagation of plasmid) was observed in our previous research, we speculated that a similar effect was occurred in strains YL27 and YL28. To resolve this issue, linearized gene fragments (see Materials and Methods) containing pYLXP'-BbxfpK-ylPAR4-ylARO10-ylARO7ylPHA2-scARO7 ${ }^{G 141 S}$ and PYLXP'-AcxpkA-ylPAR4-ylARO10ylARO7-ylPHA2-scARO7 ${ }^{G 141 S}$ were integrated at the $\mathrm{pBR}$ docking site of strain YL24, generating strains YL29 and YL30, respectively. As expected, shake flask cultivation of strains YL29 and YL30 led to a 133.64\% (679.66 $\pm 1.14 \mathrm{mg}$ /
$\mathrm{L})$ and $139.33 \%(708.58 \pm 56.52 \mathrm{mg} / \mathrm{L})$ improvement in 2-PE titer (Supplementary Figure S4), compared to the parental strain YL25. This result clearly demonstrates that manipulation of the phosphoketolase pathway is a feasible strategy to channeling carbon flux toward E4P. After this, we integrated genes $y l T K T, B b x f p K$, and AcxpkA at 26s rDNA site in strain YL24 with the helper plasmid prDNAloxP-ylTKT-Bbxf $p K$ Acxpk, obtaining strain YL31. However, expression of the 2-PE pathway (ylPAR4-ylARO10-ylARO7-ylPHA2-scARO7 $7^{\text {GI IIS }}$ ) in strain YL31 gave almost same amount of 2-PE (strain YL32, $719.67 \pm 51.14 \mathrm{mg} / \mathrm{L}$, Figure 4b) compared to strain YL30. We speculate that the engineered yeast chassis has sufficient E4P flux to maintain the shikimate pathway.

Removing Glycolytic Pathway Bottleneck to Boost Precursor PEP. To shift the metabolic equilibrium and further improve carbon flux toward shikimate pathway, we moved to boost the precursor availability of PEP. A previous study ${ }^{56}$ found that blocking the reaction of PEP to pyruvate by deleting pyruvate kinase could dramatically increase the intracellular pools of PEP. To validate this strategy in $Y$. lipolytica, we attempted to delete pyruvate kinase encoding gene $y$ IPYK (YALIOF09185g). Reports found that yeast with 

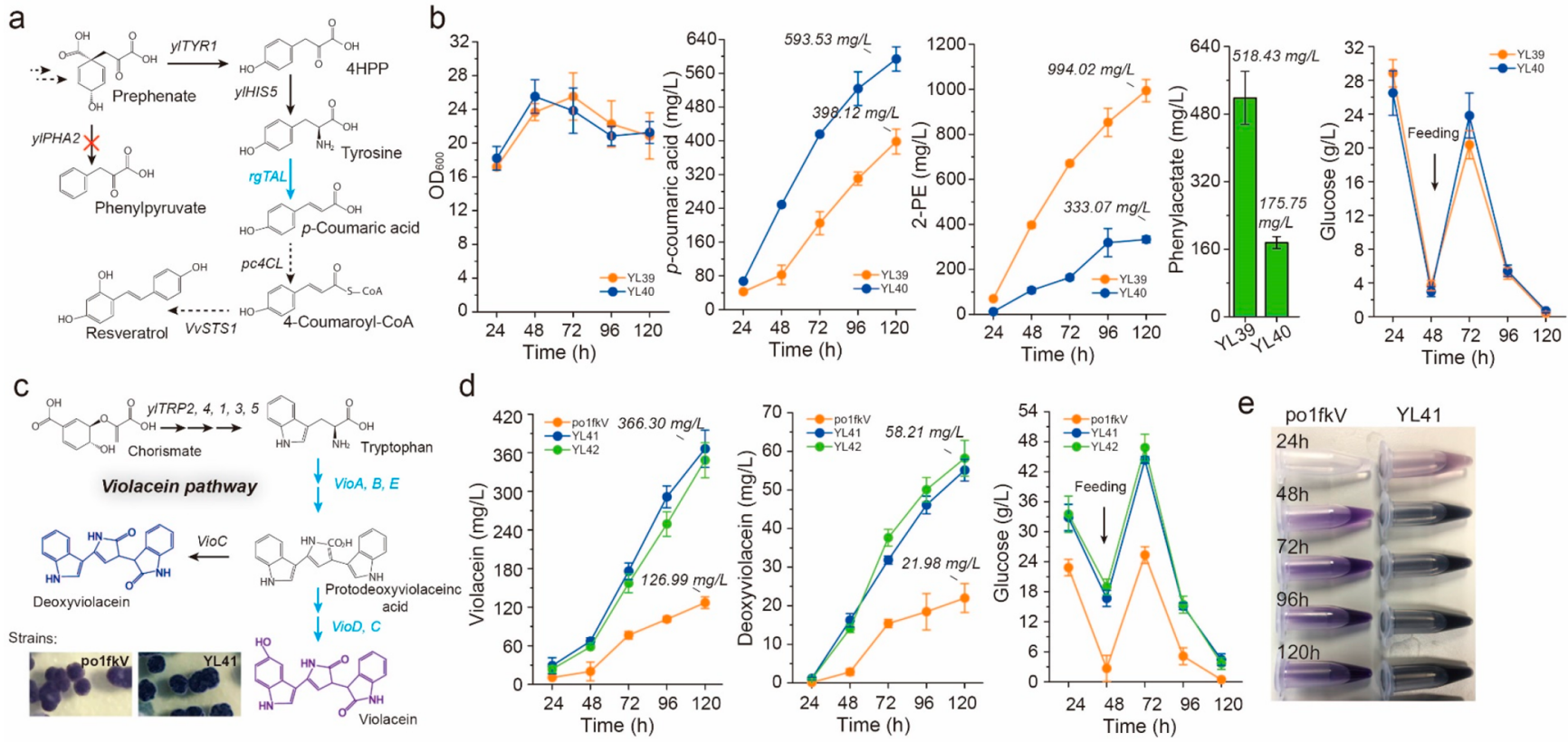

Figure 5. Harnessing Y. lipolytica chassis strain for $p$-coumaric acid and violacein production. (a) The de novo pathway for $p$-coumaric acid synthesis. (b) Phenylacetate, cell growth, $p$-coumaric acid, 2-PE, and glucose consumption profile of the engineered chassis from the de novo pathway. (c) Violacein biosynthetic pathway and yeast colonies with violacein accumulation. (d) Time profiles of violacein, deoxyviolacein, and glucose consumption of the violacein-producing strain. (e) Violacein cell culture harvested from synthetic minimal media (strain poOfkV) and YPD media (YL41). All experiments were performed in triplicate, and error bars represent standard deviations (SD).

pyruvate kinase deficiency could not grow in the complete synthetic media (CSM) with glucose as sole carbon source. ${ }^{57}$ To successfully delete $y l P Y K$ (YALIOF09185g) in YL31 background chassis, we replenished $0.5 \mathrm{~g} / \mathrm{L}$ of acetate in the selective CSM-plate (see Materials and Methods) to rescue the growth phenotype and obtained stain YL33. However, strain YL33 carrying the 2-PE pathway (ylPAR4-ylARO10-ylARO7$y l P H A 2-s c A R O 7^{G 141 S}$ ) showed a remarkable decrease in both biomass and 2-PE production in the synthetic minimal media, even with the feeding of acetate ${ }^{10}$ (stain YL34, Supplementary Figure S5). Interestingly, when the same strain (YL33) was cultivated in YPD medium with $5 \mathrm{~g} / \mathrm{L}$ sodium acetate, we observed robust cell growth (YL33 can also grow in YPD medium without acetate, as shown in Supplementary Figure S6). To this end, we integrated the 2-PE pathways (ylPAR4$\left.y l A R O 10-y l A R O 7-y l P H A 2-s c A R O 7^{G 141 S}\right)$ into chassis YL33 and cultivated YL33 with YPD medium containing $5 \mathrm{~g} / \mathrm{L}$ sodium acetate (YPA medium). The generated strain YL35 significantly improved 2-PE production to $1572.70 \pm 67.82 \mathrm{mg} / \mathrm{L}$ in YPA medium (Figure 4c). The control strain YL36 (integration of 2-PE pathway ylPAR4-ylARO10-ylARO7$y$ IPHA2-scARO7 $7^{\text {G141S }}$ in strain YL31) produced 1252.41 \pm $19.02 \mathrm{mg} / \mathrm{L}$ of 2-PE with YPA media under the same cultivation conditions. This result confirmed that blocking PEP consumption by deletion of $y l P Y K$ is a promising strategy for enlarging flux toward shikimate pathway.

Interestingly, the highest 2-PE titer of strain YL35 (1572.70 $\pm 67.82 \mathrm{mg} / \mathrm{L}$ ) was obtained at $72 \mathrm{~h}$, and subsequently, 2-PE was gradually oxidized to PEA (phenylacetic acid), which reached $1481.8 \mathrm{mg} / \mathrm{L}$ at $120 \mathrm{~h}$ (Figure 4c). We speculate that the metabolic bottleneck may be shifted from E4P/PEP to $\mathrm{NADH}$ due to the exhaustion of glucose (Figure 4d): the engineered cells need to oxidize 2-PE to generate $\mathrm{NADH}$ and maintain metabolite homeostasis. To resolve this issue, feeding with $40 \mathrm{~g} / \mathrm{L}$ of glucose effectively mitigated the synthesis of
PEA (Figure 5e). As a result, we obtained a final 2-PE titer at $2426.22 \pm 48.33 \mathrm{mg} / \mathrm{L}$ (Figure 5e). To further improve 2-PE titer, we next sought to eliminate byproducts formation in strain YL35 by knocking out $y l A L D 2, y l A L D 3$, and $y l H P D$ (encoding aldehyde dehydrogenases), resulting in strains YL37 and YL38. Deletion of genes $y l A L D 2$ and $y l A L D 3$ (strain YL37) did not significantly improve 2-PE production (2214.14 $\pm 26.48 \mathrm{mg} / \mathrm{L}$, Figure $4 \mathrm{e}$ ), in addition, further deletion of gene $y l$ HPD (strain YL38) led to a remarkable decrease in both cell growth and 2-PE production. This is possibly due to the reversibility of $y l H P D$ that contributes to the reduction of PEA to 2-PE.

In summary, we obtained the $Y$. lipolytica platform strain YL33 with optimized metabolic flux toward the shikimate pathway. This chassis strain was validated for de novo production of 2-PE at $2426.22 \pm 48.33 \mathrm{mg} / \mathrm{L}$ (strain YL35), a 286 -fold increase over the initial strain $(8.48 \pm 0.50 \mathrm{mg} / \mathrm{L})$. This is the highest 2-PE titer from the de novo pathway reported to date. To demonstrate the utility of this 2-PEproducing platform, we turned to synthesize other aromaticderived compounds, including $p$-coumaric acid (the derivative of tyrosine), resveratrol (the derivatives of $p$-coumaric acid), and violacein (the derivative of tryptophan) in the following section.

Extend the 2-PE Platform for Production of Aromatic Derivatives. In line with the optimization of 2-PE production, we decided to extend the yeast chassis to produce other aromatic derivatives, namely $p$-coumaric acid and violacein. $p$ Coumaric acid is the deamination product of tyrosine (Figure $5 a)$, which is the universal precursor in the synthesis of flavonoids, aromatic polyketides, and lignin polyphenols. ${ }^{36,58}$ By simply overexpressing a codon-optimized tyrosine ammonia lyase $\operatorname{RgTAL}$ (originating from Rhodotorula toruloides) ${ }^{34}$ and ylTYR1 (that has been deleted in the platform strain) in the yeast chassis YL33, the resulting strain YL39 produced 398.12 
$\pm 29.39 \mathrm{mg} / \mathrm{L}$ of $p$-coumaric acid with glucose supplementation (Figure $5 b$ ). However, $994.02 \pm 49.68 \mathrm{mg} / \mathrm{L}$ of $2-\mathrm{PE}$ was detected, indicating a strong competing flux from the endogenous Ehrlich pathway. Thus, we next blocked 2-PE synthesis by deleting gene ylPHA2 (encoding prephenate dehydratase), the obtained strain YL40 produced $593.53 \pm$ $28.75 \mathrm{mg} / \mathrm{L}$ of $p$-coumaric acid with yield at $7.42 \pm 0.36 \mathrm{mg} / \mathrm{g}$ glucose (Figure 5b), a 1.49-fold increase compared to the control strain. We further extend the $p$-coumaric acid pathway for resveratrol synthesis by introducing genes pc4CL (4coumarate-CoA ligase from Petroselinum crispum) and VvSTS1 (resveratrol synthase from Vitis vinifera). ${ }^{59}$ Unexpected, only $12.67( \pm 2.23) \mathrm{mg} / \mathrm{L}$ of resveratrol was detected in shake flasks (Supplementary Figure S7), indicating the existence of other rate-limiting precursors such as malonyl-CoA in the chassis strain.

Violacein is a naturally occurring purple pigment with proven chemotherapeutic activity against tumors and cancers. $^{60,61}$ Both violacein and its derivate deoxyviolacein have demonstrated a broad range of biological activities. ${ }^{60} \mathrm{By}$ introducing violacein biosynthetic genes (VioA, VioB, VioC, VioD, and VioE, Figure 5c), we previously obtained violacein production around $31 \mathrm{mg} / \mathrm{L}$ in $Y$. lipolytica. ${ }^{30,62}$ Surprisingly, overexpression of genes $y l T R P 2, y l T R P 3, V i o A, V i o B, V i o C$, $V i o D$, and VioE in strain YL33 led to the accumulation of black pigment in the fermentation broth (Supplementary Figure S8). Violacein and deoxyviolacein reached $366.30 \pm 28.99 \mathrm{mg} / \mathrm{L}$ and $55.12 \pm 2.81 \mathrm{mg} / \mathrm{L}$ (Figure $5 \mathrm{~d}$ ), which were 2.88 -fold and 2.51-fold increase over the control strain (po1fkV, $126.99 \pm$ $9.08 \mathrm{mg} / \mathrm{L}$ of violacein and $21.98 \pm 3.75 \mathrm{mg} / \mathrm{L}$ of deoxyviolacein) and 5.23-fold and 10.44-fold higher than the production reported in our previous work. ${ }^{62}$ To further improve the violacein and deoxyviolacein production, we enhanced tryptophan availability by overexpressing genes $y l T R P 5, y l T R P 4, y l T R P 3, y l T R P 2$, and $y l T R P 1$. However, no significant improvements of violacein $(348.43 \pm 27.21 \mathrm{mg} / \mathrm{L})$ and deoxyviolacein $(58.21 \pm 4.62 \mathrm{mg} / \mathrm{L})$ titer were observed in strain YL42, suggesting that the supply of tryptophan was sufficient in strain YL41 and there might be other limiting steps in the violacein pathway. Besides, we also attempted to block the chorismite-competing pathway by deleting ylARO7. No positive colonies were obtained in the background of strain YL41 with several attempts, but $y l A R O 7$ could be deleted in polfk. The specific reason for our inability to delete $y l A R O 7$ is not clear, which might be due to the metabolic burden of violacein accumulated in the cell negatively impacting cell fitness. However, the colonies with genome integration of violacein pathway (po0fkV) in YPD plate showed that use of the same promoters and terminators may lead to the occurrence of genetic instability: a minor fraction of the restreaked colonies lost the ability to produce violacein (Supplementary Figure S12). Thus, the frequency of using multiple identical promoters and terminators should be minimized when integrating several genes in one genome locus in Y. lipolytica.

Interestingly, when the violacein-producing strain YL33 was tested in the complete synthetic media (CSM-Leu), we obtained less than $50 \%(180 \mathrm{mg} / \mathrm{L})$ of violacein, compared to the violacein production with YPD media $(366.3 \mathrm{mg} / \mathrm{L})$. We speculated that the presence of tryptophan in the CSM-leu media (consisting of $50 \mathrm{mg} / \mathrm{L}$ tryptophan) might feedback inhibit the expression of critical enzymes in the violacein biosynthetic pathway. Switching to a CSM-Leu media with reduced tryptophan $(20 \mathrm{mg} / \mathrm{L})$ indeed improved violacein production to $271 \mathrm{mg} / \mathrm{L}$, indicating the presence or buildup of tryptophan strongly represses the enzyme activity in the violacein pathway. The high violacein titer $(366.3 \mathrm{mg} / \mathrm{L})$ obtained in the YPD media might be due to the slow release of tryptophan from yeast extract and peptone, which may not render feedback inhibition effect on the violacein biosynthetic pathway. While exact inhibition constants $\left(K_{\mathrm{i}}\right)$ of tryptophan to critical enzymes in the violacein biosynthetic pathway will be important for us to optimize amino acid composition in the CSM media, the use of chromosomally integrated strain cultivated in YPD media may bypass this feedback inhibition effect and improve aromatic compounds production.

Additionally, future investigations of strains YL25, YL40, and YL42 should be performed under fed-batch cultivation with benchtop bioreactors and pilot-scale tests to improve the titer, yield, and productivity of 2-PE, $p$-coumaric acid, and violacein. Major bioprocess considerations should be targeted at optimizing the culture medium, relieving 2-PE toxicity and promoting cell fitness, as well as reducing the separation and purification cost for 2-PE, $p$-coumaric acid, and violacein. Biphasic fermentation with end-product stripping might be an effective way to remove product inhibition. Considering that lignin is widely distributed in nature and it is made up with a variety of aromatic monomers, coculture of $Y$. lipolytica with lignin-degradation microbes, including Pseudomonas putida and Rhodococcus jostii et al., with solid-state or liquid cocultivation, might provide an attractive approach to valorize lignin and produce other complex aromatic derivatives.

In summary, by circumventing the intrinsic limitations of the endogenous shikimate pathway, we successfully engineered an oleaginous yeast chassis that produces $2426.22 \pm 48.33 \mathrm{mg} / \mathrm{L}$ of 2 -PE, $593.53 \pm 28.75 \mathrm{mg} / \mathrm{L}$ of $p$-coumaric acid, $366.30 \pm$ $28.99 \mathrm{mg} / \mathrm{L}$ of violacein, and $55.12 \pm 2.81 \mathrm{mg} / \mathrm{L}$ of deoxyviolacein. To the best of our knowledge (Supplementary Table S4), this result represents the highest 2-PE, violacein, and deoxyviolacein titer from the de novo shikimate pathway. This report highlights the prominent metabolic characteristics of Y. lipolytica as chassis for production of various aromatic derivatives.

\section{CONCLUSIONS}

$Y$. lipolytica is an oleaginous yeast with a superior metabolic capability to produce a large portfolio of fuels, oleochemicals, and natural products. In this work, we systematically overcame the rate-limiting steps of the endogenous shikimate pathway and built a sustainable biorefinery chassis strain for de novo synthesis of aromatics. We determined that relieving the feedback-inhibition of DAHP synthases is critical to channel flux to shikimate pathway. We also demonstrated that eliminating byproduct formation (L-Phe, L-Tyr, and L-Trp) plays an important role in mitigating the feedback regulation of DAHP synthase. Overexpression of phosphoketolase and deletion of pyruvate kinase provided a sustained metabolic source for E4P and PEP, which forms the driving force to lead carbon flux through shikimate pathway. To demonstrate the utility of our engineered $Y$. lipolytica chassis strain, three natural products, 2-PE, $p$-coumaric acid, and violacein, which were respectively derived from phenylalanine, tyrosine, and tryptophan, were chosen to test the chassis performance. With the engineered chassis Y. lipolytica, we obtained $2426.22 \pm$ $48.33 \mathrm{mg} / \mathrm{L}$ of 2 -PE, $593.53 \pm 28.75 \mathrm{mg} / \mathrm{L}$ of $p$-coumaric acid, $12.67 \pm 2.23 \mathrm{mg} / \mathrm{L}$ of resveratrol, $366.30 \pm 28.99 \mathrm{mg} / \mathrm{L}$ of 
violacein, and $55.12 \pm 2.81 \mathrm{mg} / \mathrm{L}$ of deoxyviolacein. These results highlight the metabolic versatility of $Y$. lipolytica, and the native shikimate pathway could be unlocked to produce a variety of aromatics and natural products with economic values.

\section{MATERIAL AND METHODS}

Strains, Plasmid, Primers, and Chemicals. All stains of engineered $Y$. lipolytica, including the genotypes, recombinant plasmids, and primers have been listed in Supplementary Table S1 and S2. Chemicals used in this study were all purchased from Sigma-Aldrich. Codon-optimized heterologous synthetic genes, including genes $B b x f p K, A c x p k A, \operatorname{RgTAL}, V v S T S 1$, and Pc4CL2, were ordered from GENEWIZ (Suzhou, China). Codon-optimization was performed with the IDT Web site.

Shake Flask Cultivations. For performing shake flask cultivations, seed culture was carried out in the shaking tube with $2 \mathrm{~mL}$ seed culture medium at $30^{\circ} \mathrm{C}$ and 250 r.p.m. for 48 h. Then, $0.8 \mathrm{~mL}$ of seed culture was inoculated into the 250 $\mathrm{mL}$ flask containing $30 \mathrm{~mL}$ of fermentation medium and grown under the conditions of $30{ }^{\circ} \mathrm{C}$ and 250 r.p.m. for 120 h. One milliliter of cell suspension was sampled every $24 \mathrm{~h}$ for $\mathrm{OD}_{600}$, glucose, and desired metabolism measurements.

Seed culture medium used in this study included the yeast complete synthetic media regular media (CSM, containing glucose $20.0 \mathrm{~g} / \mathrm{L}$, yeast nitrogen base without ammonium sulfate $1.7 \mathrm{~g} / \mathrm{L}$, ammonium sulfate $5.0 \mathrm{~g} / \mathrm{L}$, and CSM-Leu 0.74 $\mathrm{g} / \mathrm{L}$ ) and complex medium (YPD, containing glucose $20.0 \mathrm{~g} / \mathrm{L}$, yeast extract $10.0 \mathrm{~g} / \mathrm{L}$, and peptone $20.0 \mathrm{~g} / \mathrm{L}$ ). Fermentation medium used in this study also included the yeast complete synthetic media regular media (CSM, containing glucose 40.0 $\mathrm{g} / \mathrm{L}$, yeast nitrogen base without ammonium sulfate $1.7 \mathrm{~g} / \mathrm{L}$, ammonium sulfate $5.0 \mathrm{~g} / \mathrm{L}$, and CSM-Leu $0.74 \mathrm{~g} / \mathrm{L}$ ) and complex acetate medium (YPA, containing glucose $40.0 \mathrm{~g} / \mathrm{L}$, yeast extract $10.0 \mathrm{~g} / \mathrm{L}$, peptone $20.0 \mathrm{~g} / \mathrm{L}$, and sodium acetate $5.0 \mathrm{~g} / \mathrm{L})$.

Yeast Transformation and Screening of HighProducing Strains. The standard protocols of $Y$. lipolytica transformation by the lithium acetate method were described as previously reported. ${ }^{63,64}$ In brief, one milliliter cells was harvested during the exponential growth phase (16-24 h) from $2 \mathrm{~mL}$ YPD medium (yeast extract $10 \mathrm{~g} / \mathrm{L}$, peptone $20 \mathrm{~g} /$ $\mathrm{L}$, and glucose $20 \mathrm{~g} / \mathrm{L}$ ) in the $14 \mathrm{~mL}$ shake tube, and washed twice with $100 \mathrm{mM}$ phosphate buffer $(\mathrm{pH}$ 7.0). Then, cells were resuspended in $105 \mu \mathrm{L}$ transformation solution, containing $90 \mu \mathrm{L} \mathrm{50 \%} \mathrm{PEG4000,} 5 \mu \mathrm{L}$ lithium acetate (2 M), $5 \mu \mathrm{L}$ boiled single stand DNA (salmon sperm, denatured) and $5 \mu \mathrm{L}$ DNA products (including 200-500 ng of plasmids, lined plasmids or DNA fragments), and incubated at $39^{\circ} \mathrm{C}$ for $1 \mathrm{~h}$, then spread on selected plates. It should be noted that the transformation mixtures needed to be vortexed for $15 \mathrm{~s}$ every 15 min during the process of $39{ }^{\circ} \mathrm{C}$ incubation. The selected markers, including leucine, uracil, and hygromycin, were used in this study. All engineering strains after genetic manipulations were performed optimized screening by the shaking tube cultivations, and the optimal strain was used to perform shaking flask (these data have been shown in Supporting Information).

Single-Gene and Multigenes Expression Vectors Construction. In this work, the YaliBrick plasmid pYLXP' was used as the expression vector. ${ }^{30}$ The process of plasmid constructions also has been reported. ${ }^{65}$ In brief, recombinant plasmids of $\mathrm{pYLXP}^{\prime}-x x$ (a single gene) were built by Gibson
Assembly of linearized pYLXP' (digested by SnaBI and KpnI) and the appropriate PCR-amplified or synthetic DNA fragments. Multigenes expression plasmids were constructed based on restriction enzyme subcloning with the isocaudamers AvrII and NheI. ${ }^{66,67}$ All genes were respectively expressed by the TEF promoter with intron sequence and XPR2 terminator, and the modified DNA fragments and plasmids were sequenced by Quintarabio.

Gene Knockout. A marker-free gene knockout method based on Cre-lox recombination system was used as previously reported. ${ }^{68}$ For performing gene knockout, the upstream and downstream sequences (both $1000 \mathrm{bp}$ ) flanking the deletion targets were PCR-amplified. These two fragments, the loxPUra/Hyr-loxP cassette (digested from plasmid pYLXP'-loxPUra/Hyr by AvrII and salI), and the gel-purified plasmid backbone of pYLXP' (linearized by AvrII and salI) were joined by Gibson Assembly, giving the knockout plasmids pYLXP'loxP-Ura/Hyr-xx ( $x x$ is the deletion target). Next, the knockout plasmids were sequence-verified by Quintarabio. Then, the gene knockout cassettes were PCR-amplified from the knockout plasmids pYLXP'-loxP-Ura/Hyr-xx, and further transformed into $Y$. lipolytica. The positive transformants were determined by colony PCR. Ku70 (Po If background) was knocked out by screening more than 200 yeast colonies. Other knockout strains were built on top of the Ku70-deficient strains. Subsequently, plasmid pYLXP'-Cre was introduced into the positive transformants and promoted the recombination of loxP sites, which recycle the selected marker. Finally, the intracellular plasmid pYLXP'-Cre was evicted by incubation at $30{ }^{\circ} \mathrm{C}$ in YPD media for $48 \mathrm{~h}$. Here, Ura is the uracil marker, and $\mathrm{Hyr}$ is hygromycin marker. Specifically, for deletion of gene $y l P Y K$, final concentration of $0.5,1,1.5,2,2.5,5 \mathrm{~g} / \mathrm{L}$ acetate was added into the selective CSM-Ura plate to rescue the cell growth. Besides integration of linearized plasmid, other genomic manipulations in platform strain YL33, including gene knockout and integration of desired genes, hygromycin resistance gene was used as the selective marker grown on YPD plate containing $200 \mathrm{mg} / \mathrm{L}$ hygromycin.

Genomic Integration of Desired Genes. In this work, genomic integration of desired genes were performed in two different ways: site-specific genomic integration plasmids or application of $\mathrm{pBR}$ docking platform by linearizing the plasmid pYLXP' with digested enzyme NotI. Here, to meet specific requirements, we constructed three genomic integration plasmids pURLK, pURLA, and pHyLD, corresponding to the Ku70, YALIOE30965g (encoding acetyl-CoA hydrolase, named as Ace), and YALIOE03212g (encoding lactate dehydrogenase, named as LDH) genomic sites, respectively. The procedure of using these three plasmids was similar as that of gene knockout protocol. Plasmid maps and sequences for pURLK, pURLA, and pHyLD have been uploaded in the Supporting Information. Specifically, desired genes could be assembled into pURLX based on restriction enzyme subcloning by using the multiple cloning sites (see plasmid maps in SI files), and the integration cassettes of desired genes were retrieved by digesting plasmid pURLX- $x x$ with enzyme AvrII. Additionally, the standard protocol of $26 \mathrm{~s}$ rDNA genomic integration by plasmid prDNAloxP was used in this work, with detailed protocol described in previous work. ${ }^{6}$

The application of pBR docking platform was achieved by linearizing the plasmid $\mathrm{pYLXP}^{\prime}$ with NotI restriction enzymes. It should be noted that plasmids pYLXP'-ylPAR4-ylARO10ylARO7-ylPHA2-scARO7 $7^{G 141 S}$ and pYLXP'-VioDCBAEI have 
more than 2 NotI digestion sites, and thus, we performed sitedirected mutagenesis to change the NotI site to SnaBI site in plasmid pYLXP', generating plasmid pYLXPs'. Subsequently, gene fragments in pYLXPs'-VioDCBAE, pYLXPs' ${ }^{\prime} y l P A R 4-$ $y l A R O 10-y l A R O 7-y l P H A 2-s c A R O 7^{G 141 S}$ and its derivates were linearized by SnaBI digestion, and then the linearized fragments were integrated at genomic $\mathrm{pBR}$ docking site.

Quantification of Biomass, Glucose, 2-PE, $p$-Coumaric Acid, Resveratrol, Violacein, and Deoxyviolacein. Cell densities were monitored by measuring the optical density at $600 \mathrm{~nm}\left(\mathrm{OD}_{600}\right)$. The concentrations of 2-PE, phenylacetate, glucose, $p$-coumaric acid, resveratrol, violacein, and deoxyviolacein were all measured by high-performance liquid chromatography (HPLC) through Agilent HPLC 1220. In detail, 2-PE and penylacetate were measured at $215 \mathrm{~nm}$ under $40{ }^{\circ} \mathrm{C}$ (column oven temperature) with a mobile phase containing $50 \%(\mathrm{v} / \mathrm{v})$ methanol in water at a flow rate of 0.5 $\mathrm{mL} / \mathrm{min}$ equipped with a ZORBAX Eclipse Plus C18 column $(4.6 \times 100 \mathrm{~mm}, 3.5 \mu \mathrm{m}$, Agilent) and the VWD detector. The concentrations of glucose were measured by a Supelcogel Carbohydrate column (Sigma, USA) and a refractive index detector with $\mathrm{H}_{2} \mathrm{SO}_{4}(5 \mathrm{mM})$ as the mobile phase at a flow rate of $0.6 \mathrm{~mL} / \mathrm{min}$ at $40{ }^{\circ} \mathrm{C}$.

To quantify the concentration of $p$-coumaric acid, $0.1 \mathrm{~mL}$ of fermentation culture was mixed with 9-fold volume of absolute methanol $(100 \% \mathrm{v} / \mathrm{v})$, vortexed thoroughly, and centrifuged at 12000 r.p.m. for $10 \mathrm{~min}$. The supernatants were analyzed at $304 \mathrm{~nm}$ under $40{ }^{\circ} \mathrm{C}$ (column oven temperature) with a mobile phase containing $45 \%(\mathrm{v} / \mathrm{v})$ methanol in water at a flow rate of $0.5 \mathrm{~mL} / \mathrm{min}$ equipped with a ZORBAX Eclipse Plus C18 column $(4.6 \times 100 \mathrm{~mm}, 3.5 \mu \mathrm{m}$, Agilent $)$ and the VWD detector. To quantify the concentration of resveratrol, $0.25 \mathrm{~mL}$ of fermentation culture was mixed with an equal volume of ethyl acetate and appropriate glass beads, vortexed at $30{ }^{\circ} \mathrm{C}$ for $24 \mathrm{~h}$, and centrifuged at 12000 r.p.m. for $10 \mathrm{~min}$. Then, $100 \mu \mathrm{L}$ supernatants of top organic layer was transferred to glass vial and evaporated to dryness, then resolubilized with $100 \mu \mathrm{L}$ of methanol. Resveratrol samples were analyzed with the same HPLC protocols as $p$-coumaric acid.

To quantify the concentration of violacein and deoxyviolacein, $0.20 \mathrm{~mL}$ of fermentation culture was mixed with 5-fold volume of ethyl acetate and appropriate glass beads, vortexed at $30{ }^{\circ} \mathrm{C}$ for $24 \mathrm{~h}$, and centrifuged at 12000 r.p.m. for $10 \mathrm{~min}$. The supernatants of top organic layer were analyzed at $570 \mathrm{~nm}$ under $40{ }^{\circ} \mathrm{C}$ (column oven temperature) with a gradient method with two solvents, water (A) and methanol (B), at a flow rate of $0.4 \mathrm{~mL} / \mathrm{min}$ equipped with a ZORBAX Eclipse Plus C18 column $(4.6 \times 100 \mathrm{~mm}, 3.5 \mu \mathrm{m}$, Agilent $)$ and the VWD detector. The elution started with $100 \%$ of solvent $A$, the fraction of solvent A was decreased linearly from $100 \%$ to $20 \%$ (0-5 $\mathrm{min})$, and maintained at $20 \%$ for $3 \mathrm{~min}$ (5-8 $\mathrm{min})$, then the fraction of solvent A was increased from $20 \%$ to $100 \%$ (8$12 \mathrm{~min}$ ), and maintained at $100 \%$ for $1 \mathrm{~min}(12-13 \mathrm{~min})$.

\section{ASSOCIATED CONTENT}

\section{(s) Supporting Information}

The Supporting Information is available free of charge at https://pubs.acs.org/doi/10.1021/acssynbio.0c00185.

Supplementary Table S1, Strains and plasmids; Supplementary Table S2, Primers and oligos; Supplementary Table S3, Strain performance with product titer; Supplementary Table S4, Comparison of 2-PE titer by various microbial hosts; Supplementary Notes: Theoretical yield of the 2-PE pathway; Supplementary Figure S1, Mathematical models of 2-PE yield; Supplementary Figures S2-S12 contain byproducts (phenylacetic acid) and end-product (2-PE, $p$-coumaric acid, resveratrol, violacein and deoxyviolacein) titer, cell growth profile, yeast colony morphology of the PYKdeficient strain, yeast colony with deep purple color for violacein-producing cells et al. (PDF)

\section{AUTHOR INFORMATION}

\section{Corresponding Author}

Peng Xu - Department of Chemical, Biochemical, and Environmental Engineering, University of Maryland, Baltimore County, Baltimore, Maryland 21250, United States; 이이.org/0000-0002-0999-8546; Email: pengxu@ umbc.edu

\section{Authors}

Yang Gu - Department of Chemical, Biochemical, and Environmental Engineering, University of Maryland, Baltimore County, Baltimore, Maryland 21250, United States; Key Laboratory of Carbohydrate Chemistry and Biotechnology, Ministry of Education, Jiangnan University, Wuxi 214122, China

Jingbo Ma - Department of Chemical, Biochemical, and Environmental Engineering, University of Maryland, Baltimore County, Baltimore, Maryland 21250, United States

Yonglian Zhu - Key Laboratory of Carbohydrate Chemistry and Biotechnology, Ministry of Education, Jiangnan University, Wuxi 214122, China

Xinyu Ding - Key Laboratory of Carbohydrate Chemistry and Biotechnology, Ministry of Education, Jiangnan University, Wuxi 214122, China

Complete contact information is available at:

https://pubs.acs.org/10.1021/acssynbio.0c00185

\section{Author Contributions}

PX conceived the topic and designed the study. YG performed genetic engineering and fermentation experiments with input from JM and YL. GY and PX wrote the manuscript. PX revised the manuscript.

\section{Notes}

The authors declare the following competing financial interest(s): A provisional patent will be filed on the basis of the current work.

\section{ACKNOWLEDGMENTS}

We would like to acknowledge Bill \& Melinda Gates Foundation (grant number OPP1188443) and National Science Foundation (CBET-1805139) for financially supporting this project. The authors would also like to acknowledge the Department of Chemical, Biochemical and Environmental Engineering at University of Maryland Baltimore County for funding support. YG would like to thank the China Scholarship Council for funding support.

\section{REFERENCES}

(1) Groenewald, M., Boekhout, T., Neuveglise, C., Gaillardin, C., Dijck, P. W., and Wyss, M. (2014) Yarrowia lipolytica: safety assessment of an oleaginous yeast with a great industrial potential. Crit. Rev. Microbiol. 40, 187-206. 
(2) Xu, P., Qiao, K., and Stephanopoulos, G. (2017) Engineering oxidative stress defense pathways to build a robust lipid production platform in Yarrowia lipolytica. Biotechnol. Bioeng. 114 (7), 15211530

(3) Xu, P., Qiao, K., Ahn, W. S., and Stephanopoulos, G. (2016) Engineering Yarrowia lipolytica as a platform for synthesis of drop-in transportation fuels and oleochemicals. Proc. Natl. Acad. Sci. U. S. A. 113 (39), 10848-10853.

(4) Qiao, K., Wasylenko, T. M., Zhou, K., Xu, P., and Stephanopoulos, G. (2017) Lipid production in Yarrowia lipolytica is maximized by engineering cytosolic redox metabolism. Nat. Biotechnol. 35 (2), 173-177.

(5) Abdel-Mawgoud, A. M., Markham, K. A., Palmer, C. M., Liu, N., Stephanopoulos, G., and Alper, H. S. (2018) Metabolic engineering in the host Yarrowia lipolytica. Metab. Eng. 50, 192-208.

(6) Lv, Y., Edwards, H., Zhou, J., and Xu, P. (2019) Combining 26s rDNA and the Cre-loxP System for Iterative Gene Integration and Efficient Marker Curation in Yarrowia lipolytica. ACS Synth. Biol. 8 (3), 568-576.

(7) Lv, Y., Marsafari, M., Koffas, M., Zhou, J., and Xu, P. (2019) Optimizing oleaginous yeast cell factories for flavonoids and hydroxylated flavonoids biosynthesis. ACS Synth. Biol. 8 (11), 2514-2523.

(8) Palmer, C. M., Miller, K. K., Nguyen, A., and Alper, H. S. (2020) Engineering 4-coumaroyl-CoA derived polyketide production in Yarrowia lipolytica through a $\beta$-oxidation mediated strategy. Metab. Eng. 57, 174-181.

(9) Lv, Y., Gu, Y., Xu, J., Zhou, J., and Xu, P. (2020) Coupling metabolic addiction with negative autoregulation to improve strain stability and pathway yield. Metab. Eng. 61, 79-88.

(10) Liu, H., Marsafari, M., Wang, F., Deng, L., and Xu, P. (2019) Engineering acetyl-CoA metabolic shortcut for eco-friendly production of polyketides triacetic acid lactone in Yarrowia lipolytica. Metab. Eng. 56, 60-68.

(11) Markham, K. A., Palmer, C. M., Chwatko, M., Wagner, J. M., Murray, C., Vazquez, S., Swaminathan, A., Chakravarty, I., Lynd, N. A., and Alper, H. S. (2018) Rewiring Yarrowia lipolytica toward triacetic acid lactone for materials generation. Proc. Natl. Acad. Sci. U. S. A. 115 (9), 2096.

(12) Xue, Z., Sharpe, P. L., Hong, S. P., Yadav, N. S., Xie, D., Short, D. R., Damude, H. G., Rupert, R. A., Seip, J. E., Wang, J., Pollak, D. W., Bostick, M. W., Bosak, M. D., Macool, D. J., Hollerbach, D. H., Zhang, H., Arcilla, D. M., Bledsoe, S. A., Croker, K., McCord, E. F., Tyreus, B. D., Jackson, E. N., and Zhu, Q. (2013) Production of omega-3 eicosapentaenoic acid by metabolic engineering of Yarrowia lipolytica. Nat. Biotechnol. 31 (8), 734-40.

(13) Xie, D., Jackson, E. N., and Zhu, Q. (2015) Sustainable source of omega-3 eicosapentaenoic acid from metabolically engineered Yarrowia lipolytica: from fundamental research to commercial production. Appl. Microbiol. Biotechnol. 99 (4), 1599-610.

(14) Schwartz, C., Frogue, K., Misa, J., and Wheeldon, I. (2017) Host and pathway engineering for enhanced lycopene biosynthesis in Yarrowia lipolytica. Front. Microbiol. 8, 2233.

(15) Zhang, R., Zhang, Y., Wang, Y., Yao, M., Zhang, J., Liu, H., Zhou, X., Xiao, W., and Yuan, Y. (2019) Pregnenolone Overproduction in Yarrowia lipolytica by Integrative Components Pairing of the Cytochrome P450scc System. ACS Synth. Biol. 8, 2666-2678.

(16) Larroude, M., Celinska, E., Back, A., Thomas, S., Nicaud, J.-M., and Ledesma-Amaro, R. (2018) A synthetic biology approach to transform Yarrowia lipolytica into a competitive biotechnological producer of $\beta$-carotene. Biotechnol. Bioeng. 115 (2), 464-472.

(17) Marsafari, M., and Xu, P. (2020) Debottlenecking mevalonate pathway for antimalarial drug precursor amorphadiene biosynthesis in Yarrowia lipolytica. Metab. Eng. Commun. 10, No. e00121.

(18) Celińska, E., Ledesma-Amaro, R., Larroude, M., Rossignol, T., Pauthenier, C., and Nicaud, J.-M. (2017) Golden Gate assembly system dedicated to complex pathway manipulation in Yarrowia lipolytica. Microb. Biotechnol. 10 (2), 450-455.
(19) Larroude, M., Park, Y. K., Soudier, P., Kubiak, M., Nicaud, J. M., and Rossignol, T. (2019) A modular Golden Gate toolkit for Yarrowia lipolytica synthetic biology. Microb. Biotechnol. 12 (6), 1249-1259.

(20) Egermeier, M., Sauer, M., and Marx, H. (2019) Golden Gatebased metabolic engineering strategy for wild-type strains of Yarrowia lipolytica. FEMS Microbiol. Lett. 366 (4), fnz022.

(21) Gao, S., Han, L., Zhu, L., Ge, M., Yang, S., Jiang, Y., and Chen, D. (2014) One-step integration of multiple genes into the oleaginous yeast Yarrowia lipolytica. Biotechnol. Lett. 36 (12), 2523-2528.

(22) Gao, S., Tong, Y., Zhu, L., Ge, M., Zhang, Y., Chen, D., Jiang, Y., and Yang, S. (2017) Iterative integration of multiple-copy pathway genes in Yarrowia lipolytica for heterologous beta-carotene production. Metab. Eng. 41, 192-201.

(23) Schwartz, C. M., Hussain, M. S., Blenner, M., and Wheeldon, I. (2016) Synthetic RNA polymerase III promoters facilitate highefficiency CRISPR-Cas9-mediated genome editing in Yarrowia lipolytica. ACS Synth. Biol. 5 (4), 356-9.

(24) Yang, Z., Edwards, H., and Xu, P. (2020) CRISPR-Cas12a/ Cpfl-assisted precise, efficient and multiplexed genome-editing in Yarrowia lipolytica. Metab. Eng. Commun. 10, No. e00112.

(25) Gao, S., Tong, Y., Wen, Z., Zhu, L., Ge, M., Chen, D., Jiang, Y., and Yang, S. (2016) Multiplex gene editing of the Yarrowia lipolytica genome using the CRISPR-Cas9 system. J. Ind. Microbiol. Biotechnol. 43 (8), 1085-1093.

(26) Wagner, J. M., Williams, E. V., and Alper, H. S. (2018) Developing a piggyBac transposon system and compatible selection markers for insertional mutagenesis and genome engineering in Yarrowia lipolytica. Biotechnol. J. 13 (5), 1800022.

(27) Bredeweg, E. L., Pomraning, K. R., Dai, Z., Nielsen, J., Kerkhoven, E. J., and Baker, S. E. (2017) A molecular genetic toolbox for Yarrowia lipolytica. Biotechnol. Biofuels 10, 2.

(28) Blazeck, J., Liu, L., Redden, H., and Alper, H. (2011) Tuning gene expression in Yarrowia lipolytica by a hybrid promoter approach. Appl. Environ. Microbiol. 77 (22), 7905-7914.

(29) Liu, H., Marsafari, M., Deng, L., and Xu, P. (2019) Understanding lipogenesis by dynamically profiling transcriptional activity of lipogenic promoters in Yarrowia lipolytica. Appl. Microbiol. Biotechnol. 103 (7), 3167-3179.

(30) Wong, L., Engel, J., Jin, E., Holdridge, B., and Xu, P. (2017) YaliBricks, a versatile genetic toolkit for streamlined and rapid pathway engineering in Yarrowia lipolytica. Metab. Eng. Commun. 5, 68-77.

(31) Cui, Z., Gao, C., Li, J., Hou, J., Lin, C. S. K., and Qi, Q. (2017) Engineering of unconventional yeast Yarrowia lipolytica for efficient succinic acid production from glycerol at low pH. Metab. Eng. 42, $126-133$.

(32) Spagnuolo, M., Shabbir Hussain, M., Gambill, L., and Blenner, M. (2018) Alternative substrate metabolism in Yarrowia lipolytica. Front. Microbiol. 9, 1077.

(33) Ledesma-Amaro, R., and Nicaud, J.-M. (2016) Metabolic engineering for expanding the substrate range of Yarrowia lipolytica. Trends Biotechnol. 34 (10), 798-809.

(34) Liu, Q., Yu, T., Li, X., Chen, Y., Campbell, K., Nielsen, J., and Chen, Y. (2019) Rewiring carbon metabolism in yeast for high level production of aromatic chemicals. Nat. Commun. 10 (1), 4976.

(35) Huccetogullari, D., Luo, Z. W., and Lee, S. Y. (2019) Metabolic engineering of microorganisms for production of aromatic compounds. Microb. Cell Fact. 18 (1), 41

(36) Wang, J., Shen, X., Rey, J., Yuan, Q., and Yan, Y. (2018) Recent advances in microbial production of aromatic natural products and their derivatives. Appl. Microbiol. Biotechnol. 102 (1), 47-61.

(37) Xu, P., Marsafari, M., Zha, J., and Koffas, M. (2020) Microbial coculture for flavonoid synthesis. Trends Biotechnol. 38 (7), 686-688.

(38) Furuya, T., Arai, Y., and Kino, K. (2012) Biotechnological production of caffeic acid by bacterial cytochrome P450 CYP199A2. Appl. Environ. Microbiol. 78 (17), 6087.

(39) Lv, Y., Xu, S., Lyu, Y., Zhou, S., Du, G., Chen, J., and Zhou, J. (2019) Engineering enzymatic cascades for the efficient biotransfor- 
mation of eugenol and taxifolin to silybin and isosilybin. Green Chem. 21 (7), 1660-1667.

(40) Nthangeni, M. B., Urban, P., Pompon, D., Smit, M. S., and Nicaud, J. M. (2004) The use of Yarrowia lipolytica for the expression of human cytochrome P450 CYP1A1. Yeast 21 (7), 583-592.

(41) Hassing, E.-J., de Groot, P. A., Marquenie, V. R., Pronk, J. T., and Daran, J.-M. G. (2019) Connecting central carbon and aromatic amino acid metabolisms to improve de novo 2-phenylethanol production in Saccharomyces cerevisiae. Metab. Eng. 56, 165-180.

(42) Luttik, M. A., Vuralhan, Z., Suir, E., Braus, G. H., Pronk, J. T., and Daran, J. M. (2008) Alleviation of feedback inhibition in Saccharomyces cerevisiae aromatic amino acid biosynthesis: quantification of metabolic impact. Metab. Eng. 10 (3-4), 141-53.

(43) Li, Z., Wang, X., and Zhang, H. (2019) Balancing the nonlinear rosmarinic acid biosynthetic pathway by modular co-culture engineering. Metab. Eng. 54, 1-11.

(44) Wang, R., Zhao, S., Wang, Z., and Koffas, M. A. G. (2020) Recent advances in modular co-culture engineering for synthesis of natural products. Curr. Opin. Biotechnol. 62, 65-71.

(45) Zhang, H., Pereira, B., Li, Z., and Stephanopoulos, G. (2015) Engineering Escherichia coli coculture systems for the production of biochemical products. Proc. Natl. Acad. Sci. U. S. A. 112 (27), 8266.

(46) Celińska, E., Kubiak, P., Białas, W., Dziadas, M., and Grajek, W.

(2013) Yarrowia lipolytica: the novel and promising 2-phenylethanol producer. J. Ind. Microbiol. Biotechnol. 40 (3), 389-392.

(47) Lu, X., Wang, Y., Zong, H., Ji, H., Zhuge, B., and Dong, Z. (2016) Bioconversion of L-phenylalanine to 2-phenylethanol by the novel stress-tolerant yeast Candida glycerinogenes WL2002-5. Bioengineered 7 (6), 418-423.

(48) Wang, Z., Jiang, M., Guo, X., Liu, Z., and He, X. (2018) Reconstruction of metabolic module with improved promoter strength increases the productivity of 2-phenylethanol in Saccharomyces cerevisiae. Microb. Cell Fact. 17 (1), 60.

(49) Stark, A. H., Crawford, M. A., and Reifen, R. (2008) Update on alpha-linolenic acid. Nutr. Rev. 66, 326.

(50) Kim, B., Cho, B. R., and Hahn, J. S. (2014) Metabolic engineering of Saccharomyces cerevisiae for the production of 2phenylethanol via Ehrlich pathway. Biotechnol. Bioeng. 111 (1), 11524.

(51) Rodriguez, A., Kildegaard, K. R., Li, M., Borodina, I., and Nielsen, J. (2015) Establishment of a yeast platform strain for production of $p$-coumaric acid through metabolic engineering of aromatic amino acid biosynthesis. Metab. Eng. 31, 181-8.

(52) Gu, Y., Ma, J., Zhu, Y., and Xu, P. (2020) Refactoring Ehrlich pathway for high-yield 2-phenylethanol production in Yarrowia lipolytica. ACS Synth. Biol. 9 (3), 623-633.

(53) Bergman, A., Hellgren, J., Moritz, T., Siewers, V., Nielsen, J., and Chen, Y. (2019) Heterologous phosphoketolase expression redirects flux towards acetate, perturbs sugar phosphate pools and increases respiratory demand in Saccharomyces cerevisiae. Microb. Cell Fact. 18 (1), 25

(54) Meadows, A. L., Hawkins, K. M., Tsegaye, Y., Antipov, E., Kim, Y., Raetz, L., Dahl, R. H., Tai, A., Mahatdejkul-Meadows, T., Xu, L., Zhao, L. S., Dasika, M. S., Murarka, A., Lenihan, J., Eng, D., Leng, J. S., Liu, C. L., Wenger, J. W., Jiang, H. X., Chao, L. L., Westfall, P., Lai, J., Ganesan, S., Jackson, P., Mans, R., Platt, D., Reeves, C. D., Saija, P. R., Wichmann, G., Holmes, V. F., Benjamin, K., Hill, P. W., Gardner, T. S., and Tsong, A. E. (2016) Rewriting yeast central carbon metabolism for industrial isoprenoid production. Nature 537 (7622), 694-697.

(55) Bogorad, I. W., Lin, T. S., and Liao, J. C. (2013) Synthetic nonoxidative glycolysis enables complete carbon conservation. Nature 502 (7473), 693-697.

(56) Gu, Y., Lv, X., Liu, Y., Li, J., Du, G., Chen, J., Rodrigo, L. A., and Liu, L. (2019) Synthetic redesign of central carbon and redox metabolism for high yield production of $\mathrm{N}$-acetylglucosamine in Bacillus subtilis. Metab. Eng. 51, 59-69.

(57) Xu, Y. F., Zhao, X., Glass, D. S., Absalan, F., Perlman, D. H., Broach, J. R., and Rabinowitz, J. D. (2012) Regulation of yeast pyruvate kinase by ultrasensitive allostery independent of phosphorylation. Mol. Cell 48 (1), 52-62.

(58) Brey, L. F., Wlodarczyk, A. J., Bang Thofner, J. F., Burow, M., Crocoll, C., Nielsen, I., Zygadlo Nielsen, A. J., and Jensen, P. E. (2020) Metabolic engineering of Synechocystis sp. PCC 6803 for the production of aromatic amino acids and derived phenylpropanoids. Metab. Eng. 57, 129-139.

(59) Lim, C., Fowler, Z., Hueller, T., Schaffer, S., and Koffas, M. (2011) High-yield resveratrol production in engineered. Appl. Environ. Microbiol. 77, 3451-3460.

(60) Rodrigues, A. L., Gocke, Y., Bolten, C., Brock, N. L., Dickschat, J. S., and Wittmann, C. (2012) Microbial production of the drugs violacein and deoxyviolacein: analytical development and strain comparison. Biotechnol. Lett. 34 (4), 717-20.

(61) Sun, H., Zhao, D., Xiong, B., Zhang, C., and Bi, C. (2016) Engineering Corynebacterium glutamicum for violacein hyper production. Microb. Cell Fact. 15 (1), 148.

(62) Tong, Y., Zhou, J., Zhang, L., and Xu, P. (2019) Engineering oleaginous yeast Yarrowia lipolytica for violacein production: extraction, quantitative measurement and culture optimization, bioRxiv, June 28, 2019, 687012. DOI: 10.1101/687012 (accessed 2019-06-28).

(63) Gietz, R. D., and Woods, R. A. (2002) Transformation of yeast by lithium acetate/single-stranded carrier DNA/polyethylene glycol method. Methods Enzymol. 350, 87-96.

(64) Chen, D. C., Beckerich, J. M., and Gaillardin, C. (1997) Onestep transformation of the dimorphic yeast Yarrowia lipolytica. Appl. Microbiol. Biotechnol. 48 (2), 232-235.

(65) Wong, L., Holdridge, B., Engel, J., and Xu, P. (2019) Genetic tools for streamlined and accelerated pathway engineering in Yarrowia lipolytica. In Microbial Metabolic Engineering: Methods and Protocols (Santos, C. N. S., and Ajikumar, P. K., eds.) pp 155-177, Springer, New York, NY.

(66) Xu, P., Koffas, M. A. G., Polizzi, K., and Kontoravdi, C. (2013) Assembly of Multi-gene Pathways and Combinatorial Pathway Libraries Through ePathBrick Vectors. Methods Mol. Biol. 1073, 107-129.

(67) Xu, P., Vansiri, A., Bhan, N., and Koffas, M. (2012) ePathBrick: A synthetic biology platform for engineering metabolic pathways in E. coli. ACS Synth. Biol. 1 (7), 256-266.

(68) Fickers, P., Le Dall, M. T., Gaillardin, C., Thonart, P., and Nicaud, J. M. (2003) New disruption cassettes for rapid gene disruption and marker rescue in the yeast Yarrowia lipolytica. J. Microbiol. Methods 55 (3), 727-37. 